\title{
A European survey of noninvasive ventilation practices
}

\author{
C. Crimi ${ }^{*}$, A. Noto ${ }^{\#}$, P. Princi ${ }^{\top}$, A. Esquinas ${ }^{+}$and S. Nava ${ }^{\S}$
}

ABSTRACT: Although noninvasive ventilation (NIV) is becoming very popular, little is known about its pattern of clinical and technical utilisation in different environments.

We conducted a web-based survey in Europe to identify the perceived pattern of NIV utilisation and the reason for choosing a specific ventilator and interface type in four common clinical scenarios: acute hypercapnic respiratory failure (AHRF), cardiogenic pulmonary oedema (CPE), de novo hypoxic respiratory failure and weaning/post-extubation failure (W/PE).

A response was obtained from 272 (51.3\%) out of 530 selected European physicians involved in NIV practice. The NIV utilisation rate was higher for pulmonologists than intensivists/ anesthesiologists $(\mathbf{p}<\mathbf{0 . 0 5})$. The most common indication for all the physicians was AHRF (48\%). Physicians were more likely to use NIV dedicated ventilator in AHRF and CPE and an intensive care unit (ICU) ventilator with NIV module in de novo hypoxic respiratory failure and W/ PE, mainly because of the possibility of using the double circuit and inspiratory oxygen fraction control. Overall, the oro-nasal mask was the most frequently used interface, irrespective of clinical scenarios.

The use of NIV in Europe is generally relatively high, especially among pulmonologists and in AHRF. Dedicated NIV ventilators and ICU ventilators with NIV modules are preferably in AHRF and in de novo hypoxic respiratory failure, respectively, together with oro-nasal masks.

KEYWORDS: Europe, noninvasive ventilation, respiratory failure, survey

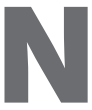
oninvasive ventilation (NIV) is well recognised as a valid strategy to avoid endotracheal intubation and its complications in selected patients with respiratory failure $[1,2]$.

Some surveys have shown that the utilisation of NIV may greatly vary depending on the geographical location and the types of environment. Between 1997 and 2002, NIV use in French intensive care units (ICUs) increased from 16\% to $24 \%$ of the total ventilated patients and from $35 \%$ to $52 \%$ of the patients starting ventilation in the ICU [3], while in other European countries and North America the utilisation rate is much lower $[4,5]$.

In certain areas, this low rate is related to lack of knowledge or experience concerning the technique, insufficient technical equipment such as specific ventilators and ad hoc interfaces, and lack of funding [4]. Despite these difficulties, NIV use has also increased outside the ICU setting, including high-dependency units, respiratory wards, emergency rooms and post-surgical recovery rooms [6-8].

Nowadays, considerable technological advances have been made by manufactures both in the development of new ventilatory modes and more sophisticated machines and interfaces, enabling physicians to choose the appropriate device for each patient.

We used an ad hoc designed web questionnaire to assess current NIV practices in various environments in Europe and in different case scenarios, placing emphasis on the technical aspects of NIV use.

\section{METHODS}

We conducted a web survey of physicians dealing with NIV in 25 European countries between January and March 2008.

The survey was sent to all members of the Respiratory Intensive Care Assembly from the European Respiratory Society (ERS), members of the Acute Respiratory Failure Group from the European Society of Intensive Care Medicine (ESICM), and physicians working in the emergency department (ED) known to be involved in NIV practice or to have published articles on the topic. Only a few members $(n=12)$ of the nonEuropean countries (mainly from the Middle East) were also included in the survey as they were members of either the ERS or the ESICM.
AFFILIATIONS

*Dept of Internal and Specialistic Medicine, Section of Respiratory Diseases, University of Catania, Catania,

\# Dept of Cardiothoracic and Vascular Anesthesia, University of Messina,

'National Research Council,

Messina, and

${ }^{\S}$ Respiratory Unit, Fondazione S.

Maugeri, Pavia, Italy,

+Intensive Care Unit, Hospital

Morales Meseguer, Murcia, Spain.

CORRESPONDENCE

S. Nava

Respiratory Unit

Fondazione S. Maugeri

Via Maugeri no 10

27100 Pavia

Italy

E-mail: stefano.nava@fsm.it

Received:

Aug 022009

Accepted after revision:

Jan 042010

First published online:

Jan 142010 
A survey instrument [9] was developed to examine physicians' knowledge, attitudes and practice about NIV use in four common clinical scenarios.

We performed individual semi-structured interviews with a group of local pulmonologists and intensivists to identify content areas and items of interest, in order to generate items and formulate questions.

Pilot testing was also performed to test content validity, reliability and relevance of the questionnaire and the ability to discriminate among respondents. Pre-testing and pilot testing were used to improve the questionnaire wording. The questionnaire showed good internal consistency and reliability with Cronbach's $\alpha \geqslant 0.78$. Clinical sensibility testing was conducted through personal interviews with four intensivists and four pulmonologists from Europe in order to evaluate the comprehensiveness, clarity and validity. The questionnaire had adequate content validity showing a content validity index of $\geqslant 0.78$.

We developed survey questions with a structured response format using multiple choice responses and Likert scales, and following this created a user-friendly web-based questionnaire.

Questions were presented on a series of linked pages (multiple-item screens) with progress indicators. Radio buttons and list box were used to encourage users to choose only one option from a predefined set of alternatives. Questions were ordered on the basis of content: broad questions on respondents' demographics and professional data; specific questions addressing physicians' experience and confidence with NIV; and scenario-based questions asking physicians about their own clinical experience with NIV in four common case scenarios: 1) acute hypercapnic respiratory failure (AHRF); 2) cardiogenic pulmonary oedema (CPE); 3) acute lung injury/ acute respiratory distress syndrome/community-acquired pneumonia/post surgical (de novo respiratory failure); 4) weaning/post-extubation failure (W/PE).

Respondents were linked to a specific scenario-based section in which they were asked to select the type of ventilator and interface they preferably choose when using NIV. We identified some variables considered to be potentially important in their choice of a specific ventilator or interface type for each clinical scenario, and asked respondents to rate their importance in the decision making process using a five-point Likert scale ranging from 1 (irrelevant) to 5 (very important).

Each physician was provided with a personal username and password giving them access to a secure internet-based questionnaire. The final surveys were e-mailed to a total of 530 physicians. Reminders were sent to clinicians who did not respond to the first e-mail within 8 weeks.

\section{Statistical analysis}

The countries were divided into three geographical areas prior to data analysis: Northern Europe; Central Europe; and Southern Europe and the Middle-East (table 1).

Descriptive statistics (means, medians and proportions) were used to report responses to survey items and to summarise respondents' characteristics. The Kruskal-Wallis test for nonparametric data was used to evaluate the variability in
NIV utilisation among different clinical scenarios and physician groups (intensivists versus pulmonologists versus others). Cochran's Q-test was used to test for the variability in the attitudes toward the use of different ventilator and mask types for each scenario.

\section{Multivariate analysis}

We conducted multivariate analysis using the "supervised learning" technique that allowed us to generate models, assuming a priori the presence of categories.

The data on ventilators were processed, generating the following model: ventilator types as category index (ICU ventilator with NIV module, ICU ventilator without NIV module, dedicated ventilator for acute NIV, home-care ventilator for chronic NIV, stand-alone continuous positive airway pressure (CPAP) generator) and the reasons for ventilator choice, plus the geographical area, physician types and clinical scenarios as variables.

In a similar way, mask data were processed, generating the following model: mask types as category index (nasal, oronasal, total face, helmet, others) and the reasons for interface choice, plus the geographical area, physician types and clinical scenarios as variables.

Each model was processed using stepwise linear discriminant analysis (STEPLDA) to determine the variables that enhance discrimination among the respective categories. New dataset created on every STEPLDA run contained the original category index and objects but only the most discriminant variables. The K-nearest neighbor ( $\mathrm{kNN}$ ) algorithm was applied for each new dataset to estimate the accuracy of the models and discrimination capability.

Statistical analysis was performed using SPSS version 15 (SPSS Inc., Chicago, IL, USA) and PARVUS 2008 [10]. A probability value of $p<0.05$ was considered to be statistically significant.

\section{RESULTS}

$272(51.3 \%)$ of 530 physicians (133 pulmonologists, 109 intensivists/anesthesiologists and 30 others) responded to the survey. Respondents' characteristics are shown in table 2. Scenario, ventilator and mask distribution in countries with the highest number of respondents are shown in table 3.

\section{Rate of NIV utilisation}

The NIV utilisation rate was significantly higher for pulmonologists $(52.9 \%$ reported $>20 \%$ of patients treated with NIV per year) versus intensivists/anesthesiologists (34.3\%) versus others $(12.6 \%)(p<0.05)$. Among the scenarios, physicians rated AHRF as the most common indication for the use of NIV (48.06\%)

Overall, attitudes toward the use of NIV in clinical settings differed significantly among the groups of physician respondents (fig. 1). Pulmonologists were more likely to use NIV in the treatment of AHRF compared to intensivists (58.9\% versus $35.2 \%$ ). Conversely the latter were more likely to use NIV in patients with CPE ( $18.7 \%$ versus $7.2 \%)$, de novo respiratory failure $(19.1 \%$ versus $6.2 \%)$ and $\mathrm{W} / \mathrm{PE}(14.4 \%$ versus $8.5 \%),(\mathrm{p}<0.05)$. 


\begin{tabular}{|c|c|}
\hline TABLE 1 & \\
\hline \multicolumn{2}{|l|}{ Northern Europe } \\
\hline Denmark & $2(0.74)$ \\
\hline Estonia & $1(0.37)$ \\
\hline Finland & $3(1.10)$ \\
\hline The Netherlands & $3(1.10)$ \\
\hline Norway & $6(2.21)$ \\
\hline Russian Federation & $1(0.37)$ \\
\hline Sweden & $5(1.84)$ \\
\hline UK & $17(6.25)$ \\
\hline Total & 38 \\
\hline \multicolumn{2}{|l|}{ Central Europe } \\
\hline Austria & $1(0.37)$ \\
\hline Belgium & $9(3.31)$ \\
\hline Czech Republic & $1(0.37)$ \\
\hline France & $27(9.93)$ \\
\hline Germany & $22(8.09)$ \\
\hline Poland & $1(0.37)$ \\
\hline Switzerland & $10(3.68)$ \\
\hline Total & 71 \\
\hline \multicolumn{2}{|c|}{ Southern Europe and the Middle East } \\
\hline Egypt & $1(0.37)$ \\
\hline Greece & $7(2.57)$ \\
\hline Iran & $1(0.37)$ \\
\hline Italy & $91(33.46)$ \\
\hline Oman & $2(0.74)$ \\
\hline Portugal & $3(1.10)$ \\
\hline Qatar & $1(0.37)$ \\
\hline Romania & $2(0.74)$ \\
\hline Spain & $48(17.65)$ \\
\hline Turkey & $7(2.57)$ \\
\hline Total & 163 \\
\hline Overall total & 272 \\
\hline
\end{tabular}

Data are presented as $n(\%)$ of respondents or $n$.

\section{Ventilator choice}

Figure 2 shows ventilator distribution among the four clinical scenarios and for each type of physician.

In AHRF patients, physicians were more likely to use NIV dedicated ventilator, compared to an ICU ventilator with NIV module or other types of ventilators $(\mathrm{p}<0.01)$.

In CPE, NIV dedicated ventilators and ICU ventilators with NIV module were mostly used, with stand-alone CPAP generator employed by $\sim 23 \%$ of the respondents (nonsignificant).

In de novo respiratory failure and $\mathrm{W} / \mathrm{PE}$ scenarios we found similar distribution rates: an ICU ventilator with NIV module was significantly more widely used than NIV dedicated ventilator $(p=0.02$ and $p=0.01$ for de novo respiratory failure and $\mathrm{W} / \mathrm{PE}$, respectively). Considering the distribution of ventilators based on physician qualification and regardless of the scenario, the most frequent ventilator type used during NIV by the intensivists/anesthesiologists was the ICU ventilator with NIV module, conversely NIV dedicated ventilator was the preferred choice of pulmonologists (fig. 2b).

\section{TABLE 2 Respondents' characteristics}

$\begin{array}{lc}\text { Field of expertise } & \\ \text { Intensive care/anaesthesia } & 104(38.24) \\ \text { Pulmonary medicine } & 136(50.00) \\ \text { Others } & 32(11.77) \\ \text { Hospital } & \\ \text { Community hospital } & 110(40.44) \\ \text { University hospital } & 162(59.56) \\ \text { Work facility } & \\ \text { ICU } & 109(40.07) \\ \text { RICU/rehab/pulmonary } & 133(48.90) \\ \text { Others } & 30(11.03) \\ \text { Beds per unit n } & \\ 1-5 & 27(9.93) \\ 6-10 & 71(26.10) \\ 11-15 & 56(20.59) \\ 16-20 & 52(19.12) \\ >20 & 66(24.26) \\ \text { Patients ventilated with NIV per yr } & \\ 0 & 10(3.68) \\ <20 \% & 41(15.07) \\ 21-40 \% & 68(25) \\ 41-60 \% & 50(18.38) \\ 61-80 \% & 36(13.24) \\ 81-100 \% & 67(24.63) \\ \end{array}$

Data are presented as n (\%) of respondents. ICU: intensive care unit; RICU: respiratory ICU; NIV: noninvasive ventilation.

The reasons for choosing a specific ventilator, as assessed using the discriminant analysis, are shown in figure 3a. In decreasing order of power, the significant parameters which provided distinction among the ventilator types were: double circuit; inspiratory oxygen fraction $\left(\mathrm{Fi}_{\mathrm{i}} \mathrm{O}_{2}\right)$ control; ease of transport; monitoring capability; drug delivery; and possibility of setting alarms. The ability of each parameter in discriminating among ventilators was investigated using a kNN classifier. The previously mentioned parameters, together with physician types $(\mathrm{F}=36.3)$, had a $\mathrm{kNN}$ of $76.4 \%$ for ICU ventilator with NIV module and $65.8 \%$ for NIV dedicated ventilator (fig. $3 b$ ).

\section{Interface choice}

Interface preferences were not influenced by clinical scenarios and the oro-nasal mask was the most frequently used overall $(p<0.01)$ (fig. 4a), irrespective of the type of physician (fig. 4b).

Geographical area (i.e. greater use of the helmet and total face mask in Southern Europe), patient comfort, multiple patient use, leaks and costs were factors significantly associated with mask choice (fig. 5a). The ability of each parameter in discriminating among interfaces, investigated using a $\mathrm{kNN}$ classifier, showed that the previously mentioned parameters, together with the physician type $(\mathrm{F}=4.5)$, had a $\mathrm{kNN}$ of $88.9 \%$ for the oro-nasal mask (fig. 5b).

\section{Humidification}

As shown in figure 6, the humidification use, as assessed by a dichotomic response (yes/no), was $>50 \%$ in all the clinical scenarios except for CPE. 


\begin{tabular}{|c|c|c|c|c|c|c|}
\hline \multirow[t]{2}{*}{ TABLE 3} & \multicolumn{6}{|c|}{$\begin{array}{l}\text { Scenarios, ventilators and mask distribution } \\
\text { among countries with the highest number of } \\
\text { respondents }\end{array}$} \\
\hline & & Germany & Spain & France & UK & Italy \\
\hline \multicolumn{7}{|l|}{ Scenarios } \\
\hline \multicolumn{2}{|c|}{ Acute hypercapnic respiratory failure } & 41.5 & 42.9 & 46.1 & 53.9 & 46.3 \\
\hline \multicolumn{2}{|c|}{ Cardiogenic pulmonary oedema } & 14.3 & 19.5 & 16.3 & 8.9 & 17.2 \\
\hline \multicolumn{2}{|c|}{ De novo hypoxic respiratory failure } & 8.0 & 12.1 & 17.1 & 6.1 & 12.3 \\
\hline \multicolumn{2}{|c|}{ Weaning/post-extubation failure } & 18.8 & 8.7 & 12.7 & 11.2 & 9.4 \\
\hline \multicolumn{7}{|c|}{ Ventilators } \\
\hline \multicolumn{2}{|c|}{ ICU ventilator with NIV module } & 25.0 & 27.1 & 61.1 & 14.7 & 32.1 \\
\hline \multicolumn{2}{|c|}{ ICU ventilator without NIV module } & 1.1 & 2.6 & 2.8 & 0 & 3.3 \\
\hline \multicolumn{2}{|c|}{ Dedicated ventilator for acute NIV } & 37.5 & 35.4 & 28.7 & 41.2 & 27.5 \\
\hline \multicolumn{2}{|c|}{ Home-care ventilator for chronic NIV } & 15.9 & 4.7 & 0.9 & 14.7 & 7.4 \\
\hline \multicolumn{2}{|c|}{ Stand-alone CPAP generator } & 1.1 & 8.9 & 0.9 & 5.9 & 10.2 \\
\hline \multicolumn{7}{|c|}{ Masks } \\
\hline \multicolumn{2}{|c|}{ Nasal mask } & 14.8 & 1.6 & 3.7 & 8.8 & 3.6 \\
\hline \multicolumn{2}{|c|}{ Oro-nasal mask, i.e. facial } & 65.9 & 67.2 & 75.0 & 58.8 & 51.6 \\
\hline \multicolumn{2}{|c|}{ Total face mask } & 0 & 4.7 & 14.8 & 8.8 & 9.9 \\
\hline \multicolumn{2}{|c|}{ Helmet } & 0 & 2.1 & 0.9 & 0 & 13.5 \\
\hline \multicolumn{2}{|c|}{ Anaesthesia mask } & 0 & 3.1 & 0 & 0 & 1.9 \\
\hline
\end{tabular}

Data are presented as percentage of respondents. ICU: intensive care unit; NIV: noninvasive ventilation; CPAP: continuous positive airway pressure.

\section{DISCUSSION}

Despite the increased amount of scientific evidence in the last 10-15 yrs, the "real life" application of NIV is only partially known. An international survey conducted in 2004 demonstrated that the use of NIV in ICUs around the world is $\sim 12 \%$ of the ventilated patients [5]. However, in 1999 the same authors showed a much lower rate of NIV utilisation in the same ICUs, thus it was speculated that the increasing scientific evidence may have influenced this trend [5].

Geographical differences were also highlighted: the rate of NIV utilisation in certain European countries is quite high [3], while in other European Countries [11, 12] and North America [4] the NIV utilisation rate is lower.

From 1997 to 2002 an increase in NIV use was observed in French ICUs: from $16 \%$ to $24 \%$ of total ventilated patients and from 35 to $52 \%$ of patients starting ventilation in ICU [3]. While in the UK in 1997, 48\% of the respiratory wards were using NIV for the treatment of AHRF [12]. In German ICUs, NIV use is $<10 \%$ in most of the units [11], while in the USA in the New England acute-care hospitals the real life utilisation of NIV is $\sim 20 \%$ [4]. Recently, it has also been shown that in EDs across the USA, the perceived use of NIV is $<30 \%$ considering the most "popular" indications (AHRF, CPE and asthma) [13]. Most of these data were collected in specific surveys concentrated in a single country/geographical area and in a single environment. Indeed, with very few exceptions [4], the studies were not focused on technological issues, such as ventilators and interfaces, which have very often been considered as one of the barriers that limit the use of NIV in real life.

In this large European, web-based survey we have demonstrated that the use of NIV, as perceived by the physicians, is

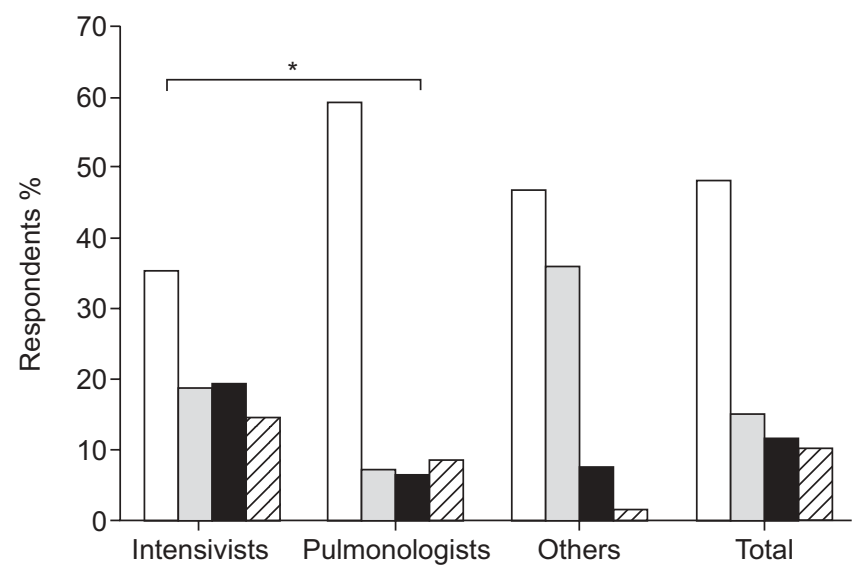

FIGURE 1. Differences in noninvasive ventilation attitudes among physicians $\square$ : acute hypercapnic respiratory failure; $\square$ : cardiogenic pulmonary oedema; $\mathbf{\square}$ : de novo acute respiratory failure; $\mathbb{\otimes}$ : weaning/post-extubation failure. * : $p<0.05$ between intensivists/anesthesiologists and pulmonologists.
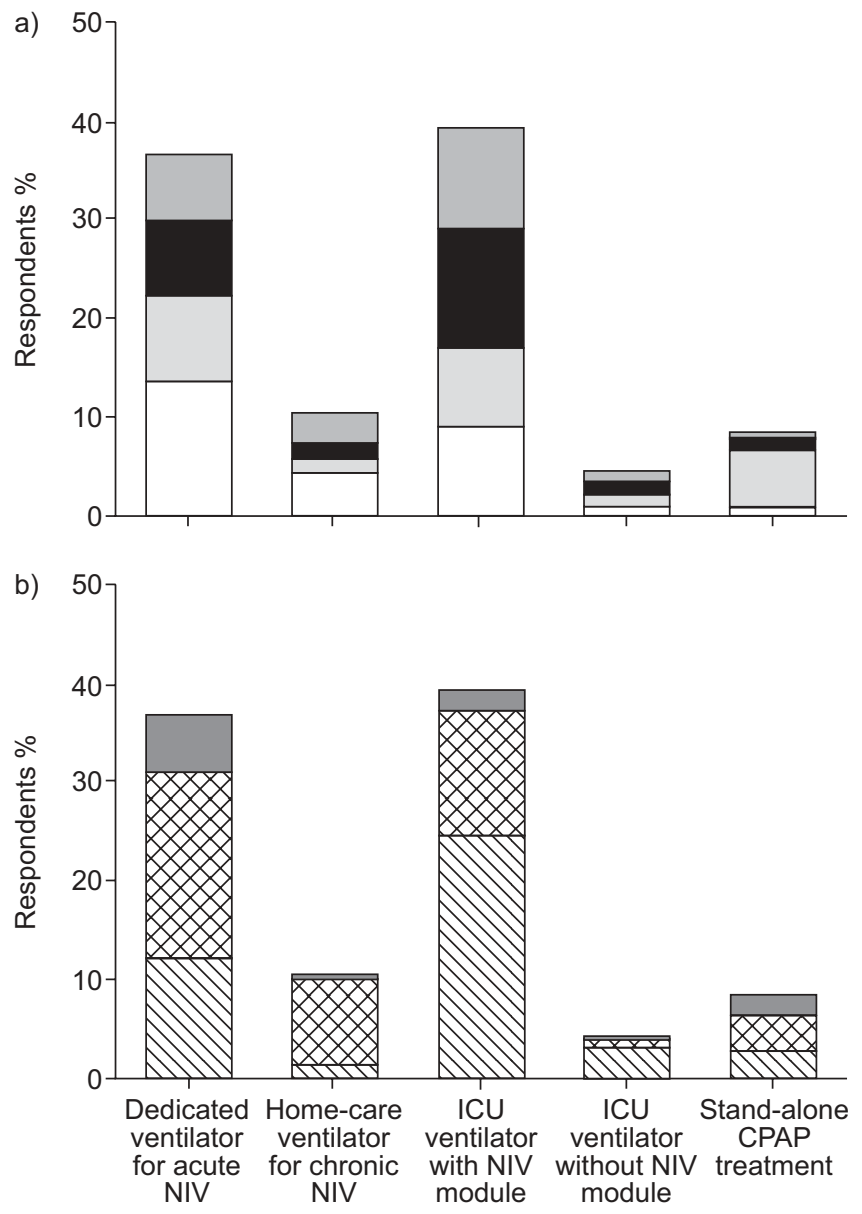

FIGURE 2. Ventilator distribution for a) each clinical case scenario and b) each type of physician. NIV: noninvasive ventilation; ICU: intensive care unit; CPAP. continuous positive airway pressure. $\square$ : acute hypercapnic respiratory failure; $\square$; cardiogenic pulmonary oedema; $\mathbf{\square}$ : de novo acute respiratory failure; $\mathbf{\square}$ : weaning/ post-extubation failure; $\mathbb{\mathbb { Q }}$ : intensivists; $\mathbf{D}$ : pulmonologists; $\mathbf{\square}$ : others. 


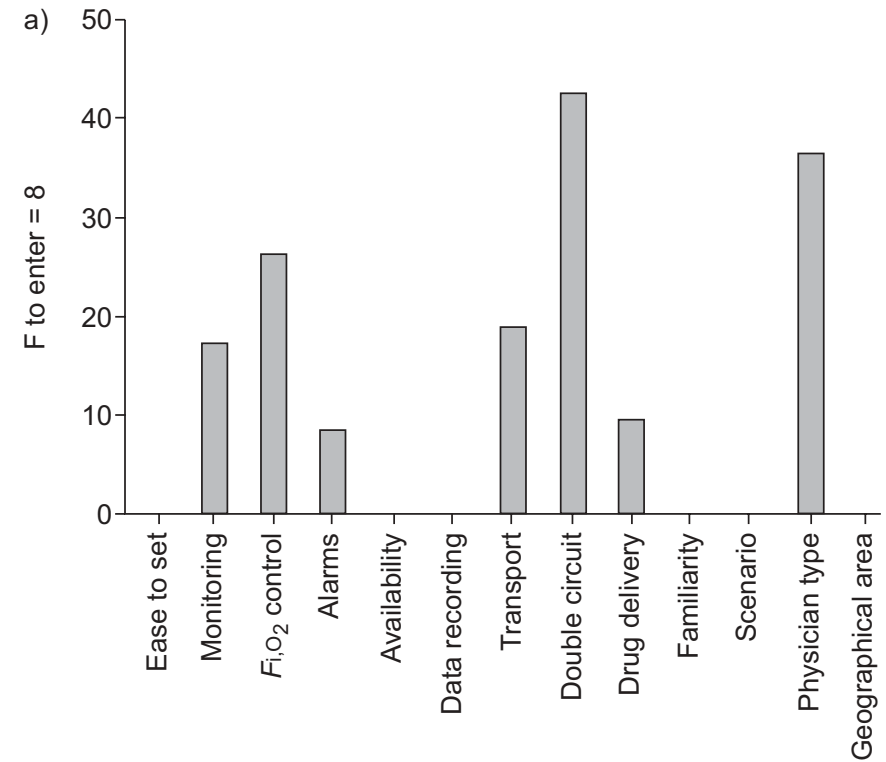

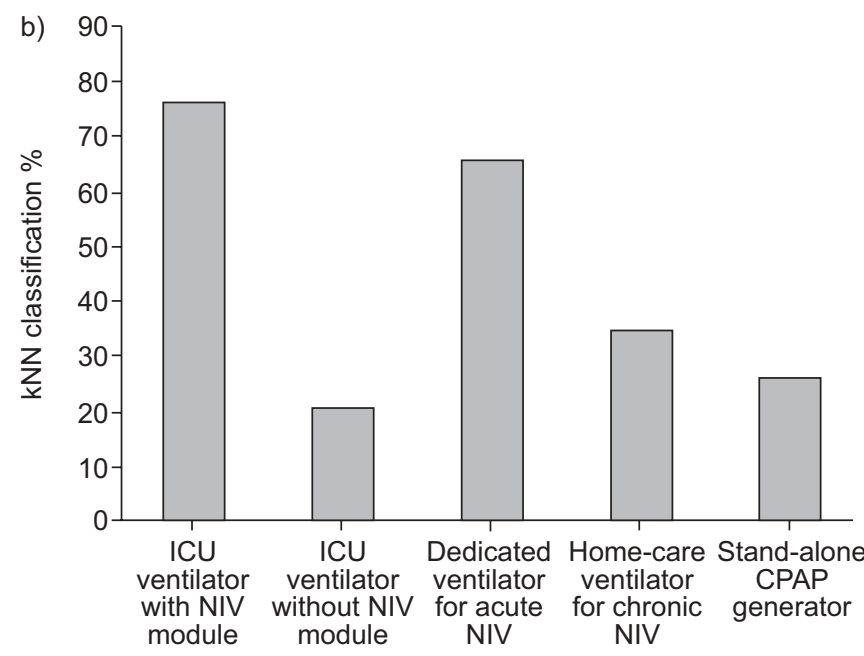

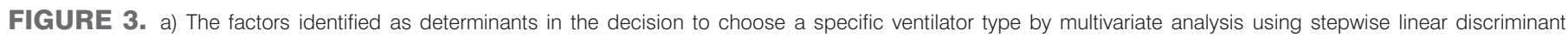

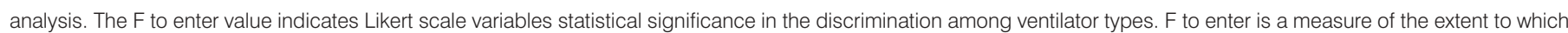

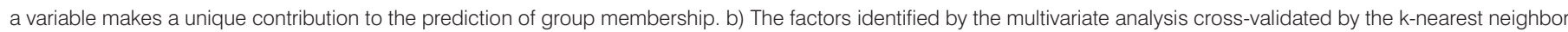

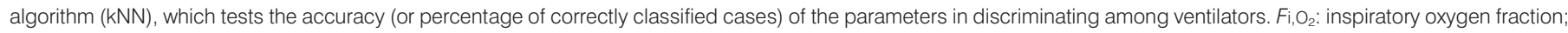
ICU: intensive care unit; NIV: noninvasive ventilation; CPAP: continuous positive airway pressure.

relatively homogeneously spread throughout the different geographical regions and considerably high, especially among pulmonologists. We have also shown that the indications for its application are those recommended by the literature. The oro-nasal interfaces are thought to be by far the most widely used interfaces in all the clinical scenarios, while dedicated NIV ventilators or ICU ventilators with an NIV module are largely utilised.

\section{Use of NIV and its indications}

Overall, we have found that the perceived NIV use among pulmonologists is higher in Europe than among intensivists and emergency medicine physicians. It is to be noted that contrariwise to North America, pulmonologists very rarely work in ICUs and their main work facilities are either the pulmonary ward or the so-called respiratory intensive care unit, which act as a step-up unit for the ward or step-down unit for the ICU, respectively. Therefore the presumed larger use of NIV among pulmonologists may depend on various reasons, including different timing of application (i.e. preventive versus alternative to intubation use) [14], severity of patients and diseases, and the fact that many patients admitted to the ED or ICU are already intubated.

In keeping with the scientific evidence, clinicians reported $\mathrm{AHRF}$ as the most common indication, following by $\mathrm{CPE}$,
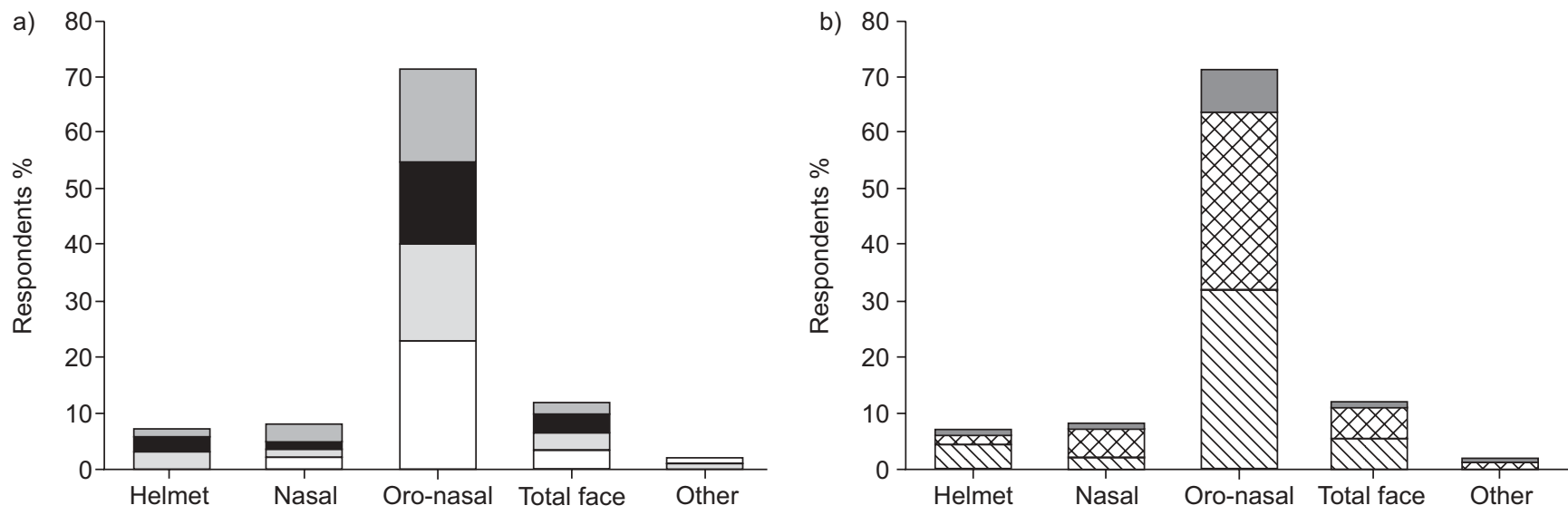

FIGURE 4. Interface distribution for a) each clinical-case scenario and b) each type of physician. $\square$ : acute hypercapnic respiratory failure; $\square$; cardiogenic pulmonary 

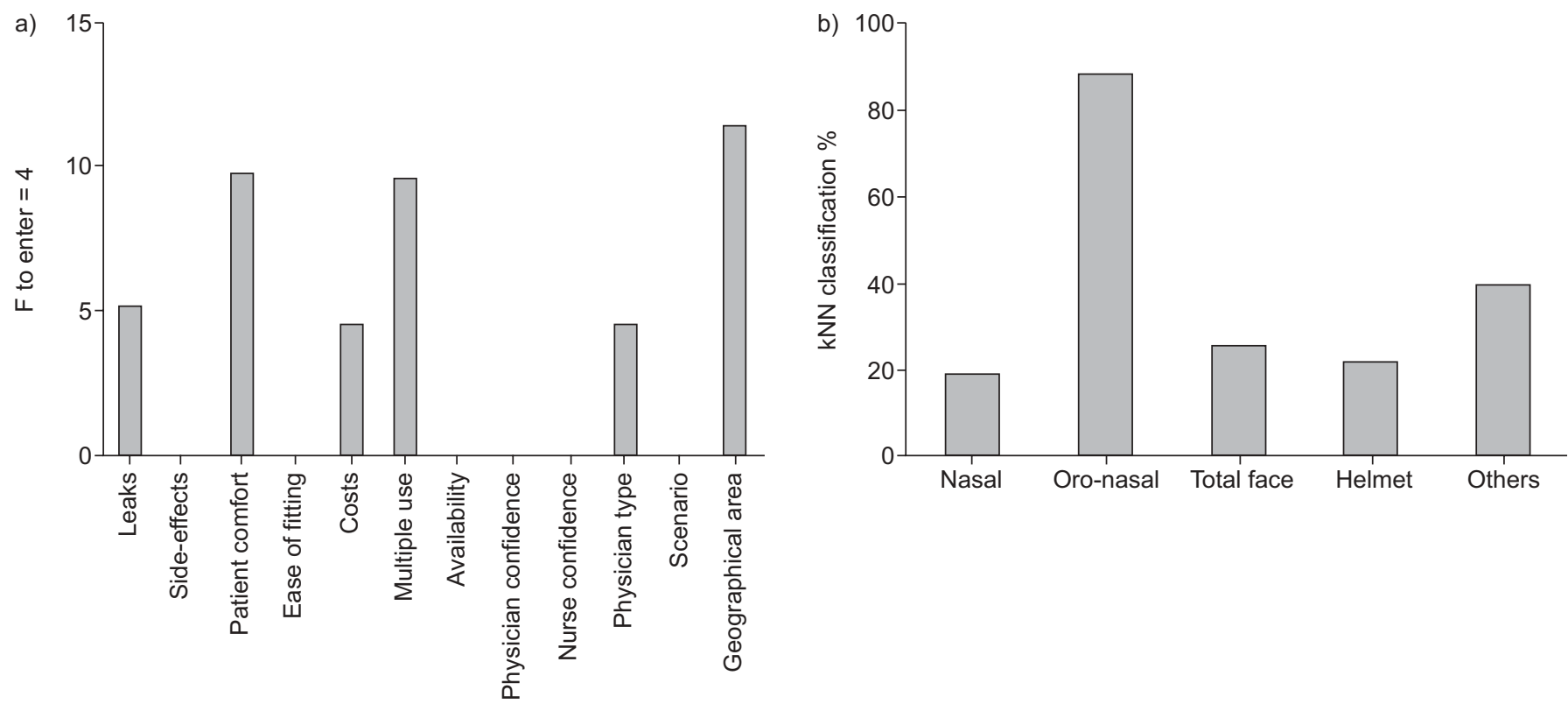

FIGURE 5. a) Factors identified as determinants in the decision to choose a specific ventilator type by multivariate analysis, using the stepwise linear discriminant analysis. The $\mathrm{F}$ to enter value indicates variable statistical significance in the discrimination between mask types. $F$ to enter is a measure of the extent to which a variable makes a unique contribution to the prediction of group membership. b) Factors identified by the multivariate analysis cross-validated by the k-nearest neighbor algorithm (KNN), which tests the accuracy (or percentage of correctly classified cases) of the parameters in discriminating among interfaces.

de novo respiratory failure and $\mathrm{W} / \mathrm{PE}$. Not surprisingly, pulmonologists were more likely to apply NIV in AHRF patients than intensivists, and the latter used it more often on hypoxaemic patients and during weaning, probably because these patients require closer monitoring and higher nurse/ patient ratio and, therefore, need to stay in the ICU.

\section{Use and reason for choosing a particular ventilator}

ICU ventilators without an NIV module and home-care ventilators were perceived to be used very seldom during an episode of acute respiratory failure. The most frequently used machines were dedicated NIV platforms especially for AHRF

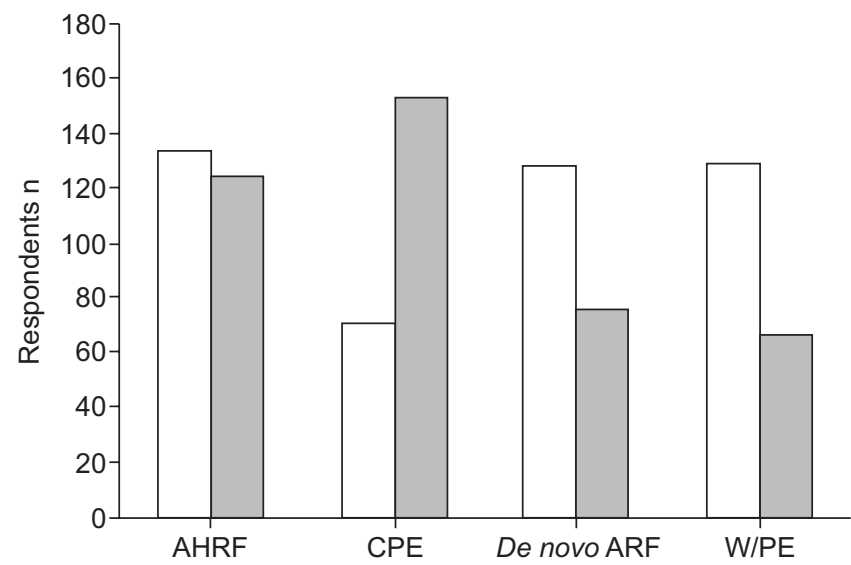

FIGURE 6. Humidification use (yes: $\square$ no: $\square$ ) among the different clinical scenarios. AHRF: acute hypercapnic respiratory failure; CPE: cardiogenic pulmonary oedema; ARF: acute respiratory failure; W/PE: weaning/post-extubation failure. and, therefore, were mainly used by pulmonologists, while ICU ventilators with an NIV module were used for other forms of acute hypoxia, mainly by intensivists. The reason for choosing a ventilator with a module able to compensate for air leaks is self-explanatory, as NIV is a semi-open ventilatory circuit where avoidance of air leaks is almost impossible and, therefore, by far the most reported side-effect [1, 2]. Despite the fact that a large variation in the ability for compensating leaks among the most common ICU ventilators was demonstrated in vitro $[15,16]$, there is agreement that, given the same setting, machine software for NIV is able to perform extremely well.

For $\mathrm{CPE},>20 \%$ of the respondents reported a preference for using CPAP, probably for its ease of use outside the protected environment and the possible short period of ventilation in this clinical situation.

The problem with $\mathrm{CO}_{2}$ re-breathing has always been a major concern of clinicians, especially among those dealing with hypercapnic respiratory failure; thus, the use of a doubletubing ventilator was a preferred option, despite the fact that many studies show that the intentional leak single circuit, when appropriately set, is able to minimise but not eliminate re-breathing $[17,18]$.

The possibility of applying a fixed and known $\mathrm{Fi}_{\mathrm{i}} \mathrm{O}_{2}$ has also been considered a safe feature, especially in those patients with de novo hypoxia. The measure of a correct arterial oxygen tension $\left(\mathrm{Pa}_{\mathrm{a}} \mathrm{O}_{2}\right) / \mathrm{Fi}_{1} \mathrm{O}_{2}$ ratio is also important as a monitoring measure, since it may better guide clinicians' decisions than when using a low flow system. In particular, it has been shown that the $\mathrm{Fi}_{\mathrm{i}} \mathrm{O}_{2}$ actually delivered using a low-flow oxygen port in the circuit varies dramatically according to the ventilator 
settings, the amount of oxygen and the position of the probe, and that it may not always deliver the same value [19].

The possibility of having a good monitoring system, together with more sophisticated alarms, highlights the problem of directly assessing patient-ventilator synchronies, especially during the very first phases of NIV. The presence of patientventilator asynchronies, especially in intubated patients, is associated with a prolonged duration of ventilation and higher incidence of tracheotomy [20].

When NIV or any other form of mechanical ventilation is applied, medical therapy should be continued, therefore respondents considered the possibility of bronchodilators' delivery during NIV to be important. This particularly holds true in chronic obstructive pulmonary disease patients where administration of bronchodilators and steroids is a paramount intervention in an attempt to reduce elastic and resistive loads. Few studies have assessed the possibility of delivering this therapy during NIV and in vivo mainly with the double-tubing system, using the same model adopted during invasive ventilation [21, 22].

\section{Use and reason for choosing a particular interface}

There was almost unanimous agreement about the perceived use of oro-nasal masks in every clinical scenario, irrespective of the type of physician involved. This is in keeping with the literature where the large majority of studies employed this type of interface [23]. It is likely that the other masks were mainly considered as a part of the "rotation strategy" when the patient showed poor tolerance to the full-face mask or in order to avoid some side-effects. In certain European countries (i.e. Italy), the helmet has been extensively used especially in the ICU, mainly for hypoxic respiratory failure and CPE [24], but overall in Europe the percentage of use is relatively small.

The main reasons for choosing a particular interface were the patient's comfort, the avoidance of leaks and the costs. The tolerance of patients to NIV is strongly related to the presence of air leaks, since it has been demonstrated that more leaks correspond to a worse compliance [25] and, in this respect, the full-face mask is much more efficient than the nasal mask [26]. Cost reduction is a major goal for clinicians; therefore, it is not surprising that the economical issue was pointed out as one of the main determinants of choice. Nowadays, improvements in technology and materials employed in assembling the interfaces enable us to use rather inexpensive masks in most of the patients. However, the most severe cases may still require sophisticated and costly interfaces.

\section{Humidification}

Humidification and warming of the inspired gas by specific devices may be needed to prevent the effects due to cool, dry gases on the trachea-bronchial epithelium during NIV [27, 28]. It is, therefore, rather surprising that humidification is employed in a relatively small percentage of patients $(\sim 55 \%)$. The dichotomic nature of the question (yes/no) did not allow us to discriminate between the use of the heated humidifiers versus heat and moisture exchangers.

\section{Strengths and limitations}

The questionnaire was based, as in most of the medical surveys, on the perception of NIV use rather than on the collection of data, which may have given a more detailed and real rate of NIV use in Europe. Another limitation is the selection of respondents, mainly based on their membership to a particular group or assembly of an international Society. This may have biased the results, since the members of a scientific Society may be more exposed and eventually prone to apply the innovations in medicine [29] as NIV may be considered. In keeping with the previous point, the majority of the respondents were from a University hospital, despite the fact that the number of non-University hospitals in Europe is higher. Therefore, the data obtained in our study may be not generalised.

The major strengths of this study are the relatively high response rate for a web survey, and the possibility of having a complete response to all the questions by every respondent, as otherwise the questionnaire could not be submitted. This was not the case for other surveys where partially completed questionnaires might affect the response rate. Indeed, in this survey only one respondent per centre was allowed to participate, avoiding repetitive answers from the same unit.

\section{Conclusions}

This study indicates that the perceived NIV use is quite high in Europe, especially among pulmonologists and less frequent among intensivists, probably because of the different timings of NIV application. The indications of the perceived NIV use are in accordance with those suggested by the international guidelines. Ventilators with NIV platform are the most frequently used machines in AHRF due to chronic obstructive pulmonary disease exacerbations, while ICU ventilators with NIV module are preferably employed in de novo hypoxic respiratory failure. Overall, the full-face interfaces are the preferred choice, irrespective of the clinical scenarios.

\section{STATEMENT OF INTEREST}

Statements of interest for P. Princi and S. Nava can be found at www. erj.ersjournals.com $/ \mathrm{misc} /$ statements.dtl

\section{REFERENCES}

1 Ambrosino N, Vagheggini G. Noninvasive positive pressure ventilation in the acute care setting: where are we? Eur Respir J 2008; 31: 874-886.

2 Nava S, Hill N. Non-invasive ventilation in acute respiratory failure. Lancet 2009; 374: 250-259.

3 Demoule A, Girou E, Richard JC, et al. Increased use of noninvasive ventilation in French intensive care units. Intensive Care Med 2006; 32: 1747-1755.

4 Maheshwari V, Paioli D, Rothaar R, et al. Utilization of noninvasive ventilation in acute care hospitals: a regional survey. Chest 2006; 129: 1226-1233.

5 Esteban A, Ferguson ND, Meade MO, et al. Evolution of mechanical ventilation in response to clinical research. Am J Respir Crit Care Med 2008; 177: 170-177.

6 Nava S, Sturani C, Hartl S, et al. End-of-life decision-making in respiratory intermediate care units: a European survey. Eur Respir J 2007; 30: 156-164.

7 Plant PK, Owen JL, Elliott MW. Early use of non-invasive ventilation for acute exacerbations of chronic obstructive pulmonary disease on 
general respiratory wards: a multicentre randomised controlled trial. Lancet 2000; 355: 1931-1935.

8 Poponick JM, Renston JP, Bennett RP, et al. Use of a ventilatory support system (BiPAP) for acute respiratory failure in the emergency department. Chest 1999; 116: 166-171.

9 Burns KE, Duffett M, Kho ME, et al. A guide for the design and conduct of self-administered surveys of clinicians. CMAJ 2008; 179 : 245-252.

10 Forina M, Leardi R, Armanino C, et al. PARVUS an extendable package of programs for data exploration, classification and correlation. Elsevier Scientific Software, 1988. www.parvus. unige.it

11 Kumle B, Haisch G, Suttner SW, et al. [Current status of noninvasive ventilation in German ICU's: a postal survey.] Anasthesiol Intensivmed Notfallmed Schmerzther 2003; 38: 32-37.

12 Doherty MJ, Greenstone MA. Survey of non-invasive ventilation (NIPPV) in patients with acute exacerbations of chronic obstructive pulmonary disease (COPD) in the UK. Thorax 1998; 53: 863-866.

13 Hess DR, Pang JM, Camargo CA Jr. A survey of the use of noninvasive ventilation in academic emergency departments in the United States. Respir Care 2009; 54: 1306-1312.

14 Nava S, Navalesi P, Conti G. Time of non-invasive ventilation. Intensive Care Med 2006; 32: 361-370.

15 Vignaux L, Tassaux D, Jolliet P. Performance of noninvasive ventilation modes on ICU ventilators during pressure support: a bench model study. Intensive Care Med 2007; 33: 1444-1451.

16 Ferreira JC, Chipman DW, Hill NS, et al. Bilevel vs ICU ventilators providing noninvasive ventilation: effect of system leaks: a COPD lung model comparison. Chest 2009; 136: 448-456.

17 Lofaso F, Brochard L, Touchard D, et al. Evaluation of carbon dioxide rebreathing during pressure support ventilation with airway management system (BiPAP) devices. Chest 1995; 108: 772-778.

18 Ferguson GT, Gilmartin M. $\mathrm{CO}_{2}$ rebreathing during BiPAP ventilatory assistance. Am J Respir Crit Care Med 1995; 151: 1126-1135.
19 Thys $\mathrm{F}$, Liistro $\mathrm{G}$, Dozin $\mathrm{O}$, et al. Determinants of $\mathrm{Fi}, \mathrm{O}_{2}$ with oxygen supplementation during noninvasive two-level positive pressure ventilation. Eur Respir J 2002; 19: 653-657.

20 Thille AW, Rodriguez P, Cabello B, et al. Patient-ventilator asynchrony during assisted mechanical ventilation. Intensive Care Med 2006; 32: 1515-1522.

21 Nava S, Karakurt S, Rampulla C, et al. Salbutamol delivery during non-invasive mechanical ventilation in patients with chronic obstructive pulmonary disease: a randomized, controlled study. Intensive Care Med 2001; 27: 1627-1635.

22 Pollack CV Jr, Fleisch KB, Dowsey K. Treatment of acute bronchospasm with $\beta$-adrenergic agonist aerosols delivered by a nasal bilevel positive airway pressure circuit. Ann Emerg Med 1995; 26: 552-557.

23 Kwok H, McCormack J, Cece R, et al. Controlled trial of oronasal versus nasal mask ventilation in the treatment of acute respiratory failure. Crit Care Med 2003; 31: 468-473.

24 Chiumello D, Pelosi P, Carlesso E, et al. Noninvasive positive pressure ventilation delivered by helmet $v$ s. standard face mask. Intensive Care Med 2003; 29: 1671-1679.

25 Prinianakis G, Delmastro M, Carlucci A, et al. Effect of varying the pressurisation rate during noninvasive pressure support ventilation. Eur Respir J 2004; 23: 314-320.

26 Girault C, Briel A, Benichou J, et al. Interface strategy during noninvasive positive pressure ventilation for hypercapnic acute respiratory failure. Crit Care Med 2009; 37: 124-131.

27 Richards GN, Cistulli PA, Ungar RG, et al. Mouth leak with nasal continuous positive airway pressure increases nasal airway resistance. Am J Respir Crit Care Med 1996; 154: 182-186.

28 Hayes MJ, McGregor FB, Roberts DN, et al. Continuous nasal positive airway pressure with a mouth leak: effect on nasal mucosal blood flux and nasal geometry. Thorax 1995; 50: 1179-1182.

29 Berwick DM. Disseminating innovations in health care. JAMA 2003; 289: 1969-1975. 